\title{
Undergraduate Medical Students' Perception about Learning in Small Group at University of Sharjah
}

\author{
Mousa Abu Ghoush, Mohammed Abdul Qadir, Zaharaa Al-Lami, Safa Al-Abdullah and Nihar Dash \\ College of Medicine, University of Sharjah, Sharjah 27272, United Arab Emirates
}

\begin{abstract}
Learning in small groups is a key instructional strategy in medicine and more so in the problem based curriculum (PBL). It is perceived that working in small groups enhances acquisition, processing and retention of the ever increasing medical knowledge. Learning in small group will help the students to be better learner and improve their personal, social and cognitive skills. The objective of this study is to describe undergraduate medical students' perception toward small group learning in a PBL curriculum. A cross-sectional descriptive study was conducted among the undergraduate medical students in the phase 2 of their MBBS program at University of Sharjah. A total of 277 undergraduate medical students participated in the study. The mean age of the study population was 20 years and $61 \%$ were female students. The most rewarding experiences as perceived by medical students were exposure to different views (71\%), making friends (57\%) improving their grades (52\%) and underwent personal development (46\%). The main disadvantages of small group learning were waste of time (55\%), side talks (16\%), and other distractions (14\%). Majority of students had a positive perception towards small group learning and agreed that it enhances their collaborative learning and team work skills. Small group learning was perceived as a key instructional method in the PBL curriculum [3] and it enhances their grades, learning outcomes, personal development and critical thinking abilities [4].
\end{abstract}

Key words: PBL, small group learning, University of Sharjah, College of Medicine.

\section{Introduction}

Traditionally, undergraduate students in medicine are divided into small groups to learn during their practical, clerkship and tutorial sessions. Each small group usually consists of 6 to 12 students and the group either functions independently or with a facilitator. With the introduction of problem and team based learning curricula in medicine, the importance of small group learning has increased significantly. Especially in problem based learning (PBL) curriculum small group learning is the fundamental instruction strategy and key to achieve the curriculum objectives and outcomes.

When it comes to learning in small group, the opinions are well diversified. While some consider it as a method of choice with bundles of benefits [1], while others have found it to be less advantageous or with negative side effects $[2,3]$. Those who

Corresponding author: Mousa Abu Ghoush, M.D., research field: medical education and epigenetics. advocate small group learning have shown evidence that it facilitate generic learning outcomes, promote skills related to lifelong learning, teamwork, communication, critical reflection, and self-directed learning [4-6] found that where students experience working in a socially cohesive group, the learning process is enhanced. For individual students, working in groups offers valuable opportunities for self-development, interpersonal growth and support. Furthermore, team learning also promotes individual student accountability, student engagement, and teamwork [7]. Productive engagement in peer interactions, collaborative reasoning and co-construction of knowledge lead to cognitive gains [8] and are therefore effective tools for promoting higher level learning [9].

In contrast, there is a parallel, strong and converging body of literature documenting students' negative perceptions $[10,11]$ and experiences of socioemotional as well as socio-cultural challenges [12]. Potential problems include unmotivated peers [13], 
communication difficulties [14], and challenges in the management of workload [15]. It is also interesting to note that when people are placed in group they lose individual responsibility and learning may in fact be suppressed due to free-rider effect [2].

The college of medicine at the University of Sharjah has a Bachelor of Medicine and Bachelor of Surgery (MBBS) program of six year duration. The college takes 100 students per year and the six years are divided into three phases. The first phase is of one year duration called foundation in medicine, the second phase is of three years called basic sciences and the last phase is of 2 years of clerkship in hospitals. The college has adopted problem based learning (PBL) curriculum since its inception in 2005. The curriculum is delivered in all the three phases through small groups of 10 to 12 students. Although the groups are assigned with facilitators most of the time to supervise their work, the groups do function independently outside the college hours.

The aim of this study was to investigate undergraduate medical students' perceptions on the values of small group learning and their perceived challenges. The results will help to understand the group dynamics, student attitudes towards small group work influence, learning and motivation experiences that will make small group learning a more productive and enjoyable experience in medicine.

\section{Materials and Methods}

This is a cross-sectional descriptive study involving undergraduate medical students in phase 2 MBBS program of the college in the academic year 2012-2013. A convenience sampling method was used and all the data were collected at one point of time. A questionnaire consisting of 35 questions (appendix 1) was used to extract information related to demographics and perception of small group learning. Three main domains were to be assessed in their perception, the social, cognitive and personal development domains. The responses were recorded on a 5 point Likert scale; 5 points for strongly agree and 1 for strongly disagree. Data was collected, entered and analyzed using "SPSS 21 " and Chi-square test was the main test used for the correlations and percentage frequencies, both of which were represented by pie and bar charts later on.

\section{Results}

A total of 277 undergraduate medical students participated in the study: $39 \%$ of the study population were males and $61 \%$ were females; the mean age of the student population was 20 years.

Of the total number of participants, $41 \%$ were involved in study groups, of whom $50 \%$ had previous practice in high school. There was clear difference in gender perception to the group dynamics and learning behaviors in small group (Fig. 4). While, one hundred forty four (52\%) students agreed that learning in small group helped to improve their grades, 19 of 277 (7\%) reported grade deterioration. According to the students, exposure to different views was the most rewarding experience (71\%) followed by making friends $(57 \%)$ and personal development (46\%).

Helping the group members with their strengths, ability to work with heterogeneous members, sharing ideas, overcoming shyness, becoming tolerant to other people views, more organized and better productivity (Fig. 5) were some of the key social and personal development achieved in small group learning. In the cognitive domain, students learned better when they explained a topic to other group members, they helped each other to clarify doubts and in the process learned deeper in to the subjects, and developed more simplified materials like concept and mind maps (Fig. 6) to help the group learning were the crucial achievements of small group learning. Some of the major disadvantages of learning in small groups were excessive time consumption to achieve a task followed by side talks and distraction during the group activities (Fig. 3). 


\begin{tabular}{|l|l|}
\hline Level of Importance as Perceived by Medical Students & \\
\hline Study Circles & $52 \%$ \\
\hline Anatomy Lab Groups & $86 \%$ \\
\hline Clinical Skills Groups & $88 \%$ \\
\hline Hospital Visits & $48 \%$ \\
\hline Problem Based Learning (PBL) & $70 \%$ \\
\hline Team Based Learning (TBL) & $77 \%$ \\
\hline
\end{tabular}

Fig. 1 Perceived importance of various types of small group learning.

\begin{tabular}{|l|l|}
\hline Most Rewarding Experience & \\
\hline Cooperative Learning Environment & $66 \%$ \\
\hline Making Friends & $57 \%$ \\
\hline Underwent Personal Development & $46 \%$ \\
\hline Exposure to different views & $71 \%$ \\
\hline
\end{tabular}

Fig. 2 Overall rewarding experiences.

\begin{tabular}{|l|l|}
\hline Disadvantages of Small Group Learning & \\
\hline Time Wasting & $55 \%$ \\
\hline Side talks & $14 \%$ \\
\hline Distraction & $7 \%$ \\
\hline Dominance & $1 \%$ \\
\hline Conflicts & $4 \%$ \\
\hline Others & $16 \%$ \\
\hline
\end{tabular}

Fig. 3 Limitations of small group learning.

You became more patient while being part of a small group

Working in a group helps you overcome your shyness

You like to help your group members with what you are good at

You also learn when you teach the material to your group members

Group memders help explain things that you don't understand

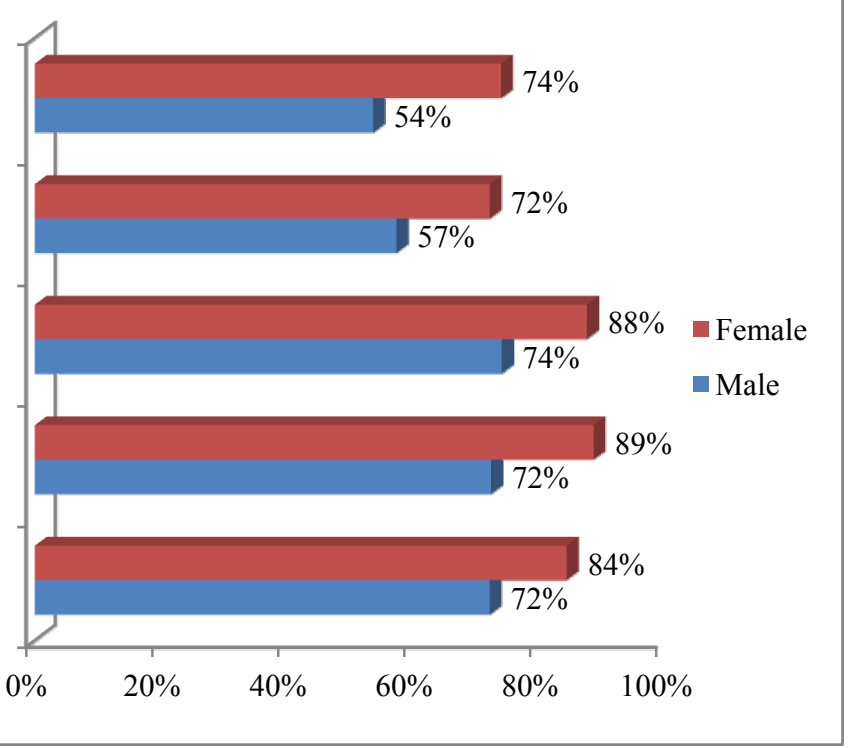

Fig. 4 Perception of learning in small groups by gender. 


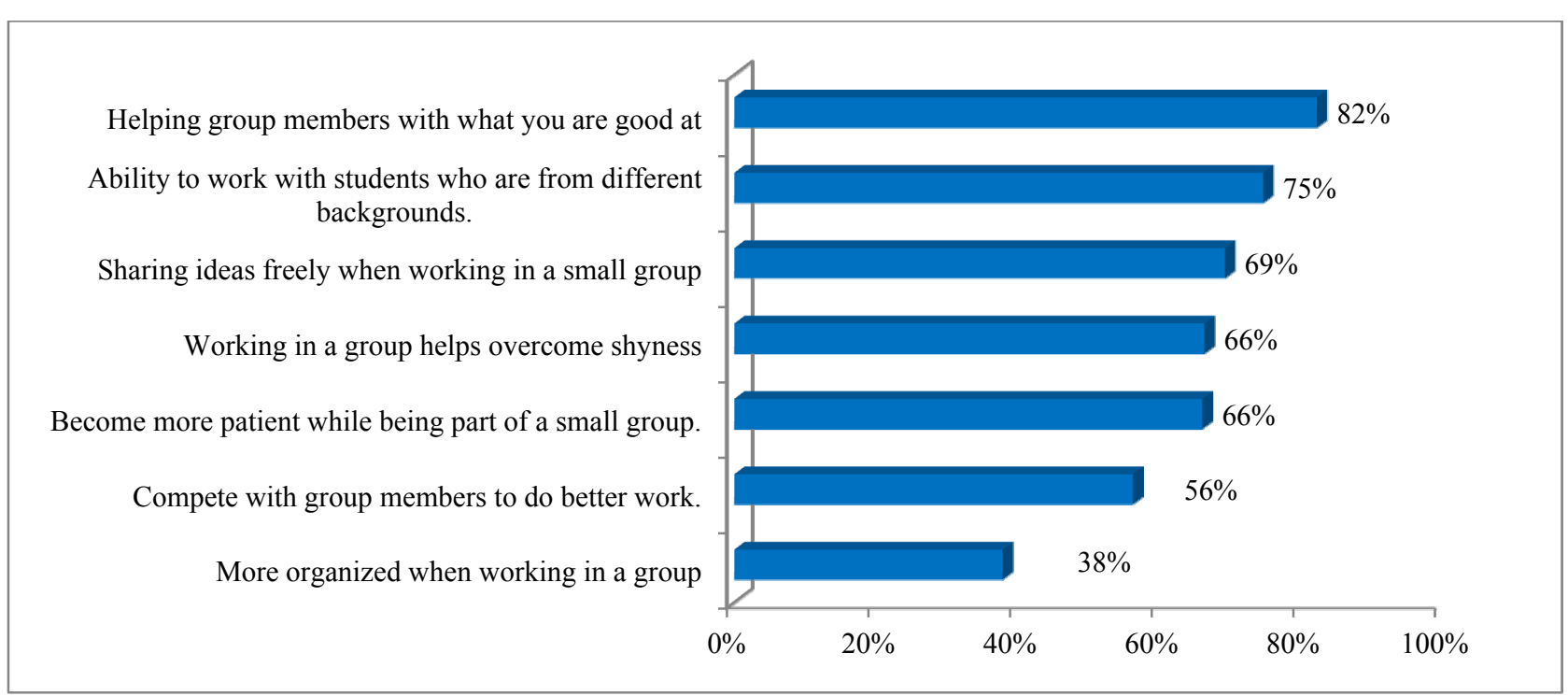

Fig. 5 Perceived benefits related to social and personal development.

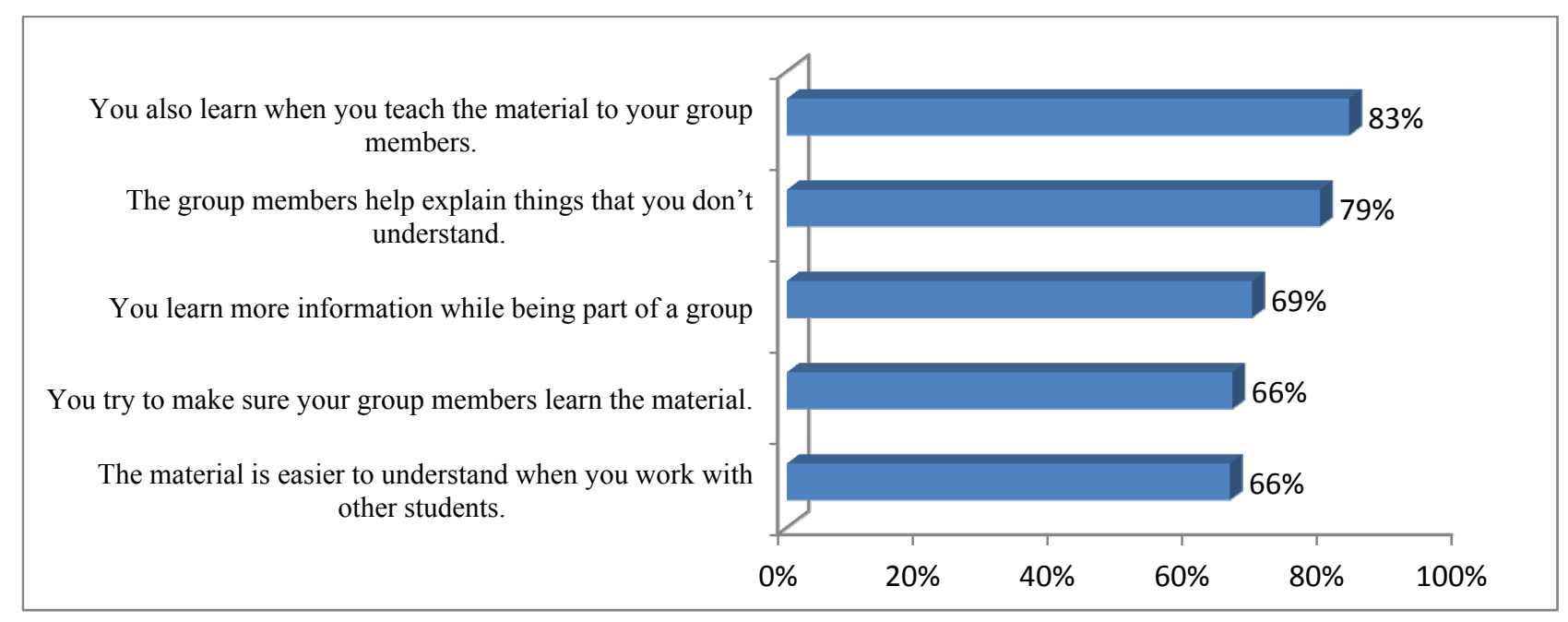

Fig. 6 Perceived benefits related to cognitive development.

\section{Discussion}

Our study showed that studying in small group in PBL based medical curriculum benefitted the students in acquisition of better knowledge, enhancement of their individual grades and improvement in their personal, social and cognitive development.

In their personal domain, the study showed that the students were able to overcome their shyness and improve their communication skills while interacting with the team members in the group. They felt more confident and realized their individual importance in the group. The small group environment is more intimate where the members develop bonding and trust amongst each other. This in turn helps the member to express themselves more clearly and has more chance to speak up. For individual students, working in small the sense of identity and belongingness plays a great role in shaping their self-development and interpersonal growth [16].

When it comes to their social interaction, the students were more open to other people views, developed patience to listen to others, they started sharing ideas, were able to critique each other in a constructive manner. Working in group taught them how to organize priorities and achieve objective in a 
time bound situation. This we believe is the true essence of collaborative learning. The small groups started to develop positive interdependence where each member believed his success is closely dependent on the success of the group [17]. This motivated them to set priorities and work in time bound manner to achieve success that all can share credit [11].

In cognitive domain, the study showed students acquire better knowledge and problem solving skills when they work in small groups which was reflected in their individual grades. The students perceived that they learn better when they try to explain certain concept to other members in the group and they collected more information's on a particular topic which means it does improved their in depth knowledge than superficial reading habits [18]. The development of group concept maps helped the members to simplify the complex concepts and put them in their own words which are easy to understand and reproduce. In PBL curriculum there is a good amount of self-study required in time bound manner to keep up with academic progress. When a student works independently, he has a chance to be lost in this vast knowledge gathering process and starts to panic. In contrast, when he is in a small group, there is a lot of mutual help and sharing that makes that process easier and rewarding [19].

Learning in small groups has its own disadvantages. Half of the study population believed that they have not utilized their time properly and were engaged in side talks and distraction during group activities. Sometime there were issues with individual talking a boss role and dominating the group and conflicts within the members while making decisions. In small group without suitable buffer this conflicts can deepen and may results in segregation of certain team members [10]. Sometime these issues can be resolved in supporting the group with facilitators and laying down ground rules [20].

The study sample size and lack of follow up of the study group in all the three phases of the curriculum are two potential limitations of this study. The plan is to overcome these limitations by including more students taking similar PBL medical curriculum and to follow them up in the phase 3 will be very interesting observations [12].

\section{Conclusions}

Majority of students had a positive perception towards small group learning and agreed that it enhances their collaborative learning and team work skills. Small group learning was perceived as a key instructional method in the PBL curriculum and it enhances their grades, learning outcomes, personal development and critical thinking abilities.

\section{Funding}

None

\section{Conflict of Interest}

Nothing to declare

\section{Ethical Approval}

Not required

\section{Acknowledgments}

We would like to extend our sincere thanks to Dr. Anwar Khursheed and Mrs. Amal Hussein for guiding us during this study.

\section{References}

[1] Johnson, D. W., Johnson, R. T., and Stanne, M. B. 2000. "Cooperative Learning Methods: A Meta-analysis." Online. Available at: https:/www.google.ae/webhp?sourceid=chrome-instant\& ion $=1 \&$ espv $=2 \&$ ie $=$ UTF- $8 \#$ q $=$ Johnson, + D.W., + Johnson, + R. + and + St+Anne, + M. (Accessed 02 May 2016).

[2] Karau, S. J., and Willimas, K. D. 1993. "Social Loafing: A Meta-Analytic Review and Theoretical Integration." Journal of Personality and Social Psychology 65 (4): 681-706.

[3] Horwitz, S. K., and Horwitz, I. B. 2007. "The Effects of Team Diversity on Team Outcomes: A Meta-Analytic Review of Team Demography." Journal of Management 33 (6): 87-1015. 
[4] Gupta, M. 2004. "Enhancing Student Learning Performance through Cooperative Learning in Physics." Assessment and Evaluation in Higher Education 29 (1): 63-73.

[5] Spalding, B., Ferguson, S., Garrigan, P., and Stewart, R. 1999. "How Effective is Group Work in Enhancing Work-based Learning? An Evaluation of an Educational Studies Course." Journal of Further and Higher Education 23 (1): 109-15.

[6] Cartney, P., and Rouse, A. 2006. "The Emotional Impact of Learning in Small Groups: Highlighting the Impact on Student Progression and Retention." Teaching in Higher Education 11 (1): 79-91.

[7] Hunt, D. P., Haidet, P., Coverdale, J. H., and Richards, B. 2003. "The Effect of Using Team Learning in an Evidence-based Medicine Course for Medical Students." Teaching and Learning in Medicine 15 (2): 131-9.

[8] van Boxtel, C., van der Linden, J., and Kanselaar, G. 2000. "Collaborative Learning Tasks and the Elaboration of Conceptual Knowledge." Learning and Instruction 10: 311-30.

[9] Amato, C. H., and Amato, L. H. 2005. "Enhancing Student Team Effectiveness: Application of Myers-Briggs Personality Assessment in Business Courses.” Journal of Marketing Education 27: 41-51. http://dx.doi.org/10.1177/0273475304273350.

[10] Pauli, R., Mohiyeddini, C., Bray, D., Michie, F., and Street, B. 2008. "Individual Differences in Negative Group Work Experiences in Collaborative Student Learning." Educational Psychology: An International Journal of Experimental Educational Psychology 28 (1): 47-58. doi: 10.1080/01443410701413746.

[11] Volet, S., and Mansfield, C. 2006. "Group Work at University: Significance of Personal Goals in the Regulation Strategies of Students with Positive and Negative Appraisals." Higher Education Research \& Development 25 (4): 341-56. doi: 10.1080/07294360600947301.
[12] Garcia-Prieto, P., Bellard, E., and Schneider, S. C. 2003. "Experiencing Diversity, Conflict, and Emotions in Teams." Applied Psychology 52 (3): 413-40. doi: 10.1111/1464-0597.00142.

[13] Bourner, J., Hughes, M., and Bourner, T. 2001. "First-year Undergraduate Experiences of Group Project Work." Assessment \& Evaluation in Higher Education 26 (1): 19-39.

[14] Salomon, G., and Globerson, T. 1989. "When Teams do not Function the Way They Ought to." International Journal of Educational Research 13 (1): 89-99. doi: 10.1016/0883-0355(89)90018-9.

[15] Fiechtner, S. B., and Davis, E. A. 1985. "Why Some Groups Fail: A Survey of Students' Experiences with Learning Groups." The Organizational Behavior Teaching Review 9 (4): 75-88.

[16] Patricia, C., and Alison, R. 2006. "The Emotional Impact of Learning in Small Groups: Highlighting the Impact on Student Progression and Retention.” Teaching in Higher Education 11 (1): 79-91.

[17] Laal, M. 2013. "Positive Interdependence in Collaborative Learning." Procedia-Social and Behavioral Sciences 93: 1433-7.

[18] Yamarik, S. 2007. "Does Cooperative Learning Improve Student Learning Outcomes?" Journal of Economic Education 38 (3): 259-77.

[19] McLean, M., Van Wyk, J. M., Peters-Futre, E. M., and Higgins-Opitz, S. B. 2006. "The Small Group in Problem-based Learning: More than a Cognitive 'Learning' Experience for First-year Medical Students in a Diverse Population.” Med. Teach. 28 (4): e94-103.

[20] Lendrum, A., Humphrey, N., Kalambouka, A., and Wigelsworth, M. 2009. "Implementing Primary Social and Emotional Aspects of Learning (SEAL) Small Group Interventions: Recommendations for Practitioners." Emotional \& Behavioural Difficulties 14 (3): 229-38. doi:10.1080/13632750903073509. 
Appendix

\section{Questionnaire}

1. Gender:
(1) Male
(2) Female

2. Age: years

3. Nationality:

4. Specify your academic year:
(1) Year 1
(3) Year 2
(4) Year 3

5. Were you part of small groups before joining college?
(1) Yes
(2) NO

6. Specify your educational system during high school:
(1) British
(2) American
(3) Ministry of education (UAE)
(4) Others Please Specify:

7. How often are you involved in small group learning?
(1) Never
(2) Rarely
(3) Sometimes
(4) Often
(5) Always

8. Are you part of small study groups?
(1) YES
(2) $\mathrm{NO}$

Please tick the appropriate scores on the Likert scale.

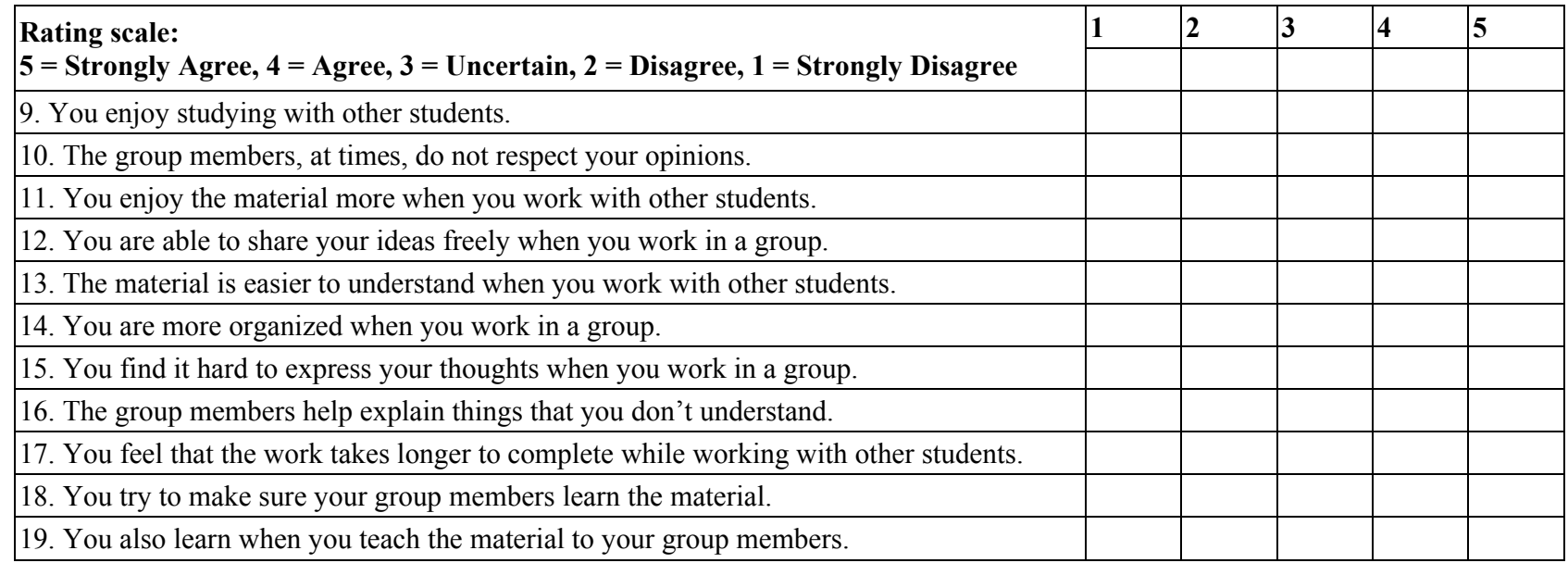




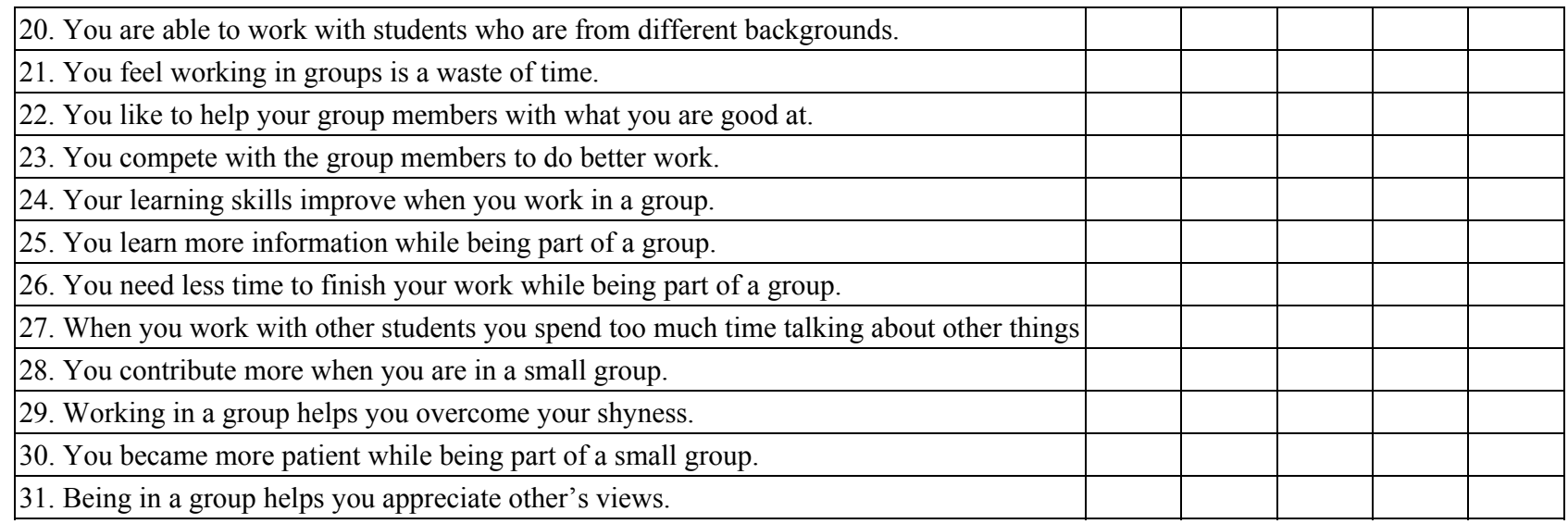

32. In your opinion, rate the following as methods of promoting interactive learning.

\begin{tabular}{|l|l|l|l|l|l|l|l|l|l|l|}
\hline \multicolumn{7}{|c|}{ 1-Not at all important, 2-Low importance, 3-Slightly important, } \\
\hline S. No & Description & $\mathbf{1}$ & $\mathbf{2}$ & $\mathbf{3}$ & $\mathbf{4}$ & $\mathbf{5}$ & $\mathbf{6}$ & $\mathbf{7}$ \\
\hline$(1)$ & Study Circles & & & & & & & \\
\hline$(2)$ & Anatomy lab groups & & & & & & & \\
\hline$(3)$ & Clinical Skills group & & & & & & & \\
\hline$(4)$ & PBL & & & & & & & \\
\hline
\end{tabular}

33. In your opinion, which of the following was a rewarding experience in being part of a small group?

(1) Cooperative learning environment

(2) Making friends

(3) Underwent personal development

(4) Exposure to different views

(5) Others: (Specify)

34. In your opinion, what are the advantages of small group learning?

35. In your opinion, what are the disadvantages of small group learning? 